\title{
STUDY OF THE INFLUENCE OF THE STRATOSPHERIC WARMING IN JANUARY, 2013 ON THE VERTICAL STRUCTURE OF OZONE AND TEMPERATURE IN THE MIDDLE ATMOSPHERE OVER TOMSK USING MICROWAVE AND LIDAR DIAGNOSTICS
}

\author{
G.G. Matvienko ${ }^{1}$, Y.Y. Kulikov² ${ }^{2}$, V.N. Marichev ${ }^{1}$, D.A.Bochkovsky ${ }^{1}$, A.A. Krasilnikov ${ }^{2}$, \\ V.G. Ryskin ${ }^{2}$. \\ ${ }^{1}$ V.E. Zuev Institute of Atmospheric Optics, Siberian Branch of the Russian Academy of Sciences, \\ Academician Zuev Square, Tomsk 634021, Russia, E-mail: mgg@iao.ru \\ ${ }^{2}$ Institute of Applied Physics, Russian Academy of Sciences, \\ 46 Ulyanov St., Nizhny Novgorod 603950, Russia, E-mail: yuyukul@appl.sci-nnov.ru
}

\section{INTRODUCTION}

The study of response of the middle atmosphere (stratosphere and mesosphere) to any external impact (variations of sunlight, flux of cosmic ray particles, eruptions of volcanoes, and anthropogenesis factors) is an urgent physical problem. Ozone and temperature are important atmospheric parameters. The correlation of these parameters is of significant interest from the viewpoint of thermal balance of the middle atmosphere. The basic heating of the stratosphere (altitude range of $20-50 \mathrm{~km}$ ) is caused by absorption of solar ultraviolet radiation by ozone molecules. Thermal changes influence the rate of ozone formation and destruction. Other types of wave processes can redistribute the structures of vertical profiles of ozone and temperature in the middle atmosphere. Sudden stratospheric warming affects a lot of widely known atmospheric wave processes. Microwave radiometry and Rayleigh lidar allow investigation of ozone and temperature variations during largescale wave disturbances in the middle atmosphere, such as, for example, stratospheric warming [1-3].

\section{METHODOLOGY}

Experiment was arranged in the following manner. Measurements were conducted with a mobile microwave ozonemeter [4]. A microwave instrument consisted of an uncooled millimeter wave receiver and a multichannel spectrometer. Device was tuned at the frequency of ozone rotational transition at $110836.04 \mathrm{MHz}$. A receiver converts millimeter wave signals at its input to lower intermediate frequencies (IF) through heterodyning with a local oscillator. The characteristics of the microwave instrument (mobile ozonemeter) were the following: single sideband noise temperature of $2500 \mathrm{~K}$, analysis bandwidth of $240 \mathrm{MHz}$, spectral resolution of 1 to
$10 \mathrm{MHz}$, and number of spectral channels of 31 . The ozonemeter allowed measurement of atmospheric ozone line with a time resolution 20 min and an accuracy of $\sim 2 \%$. Figure 1 shows the general view of the microwave equipment.

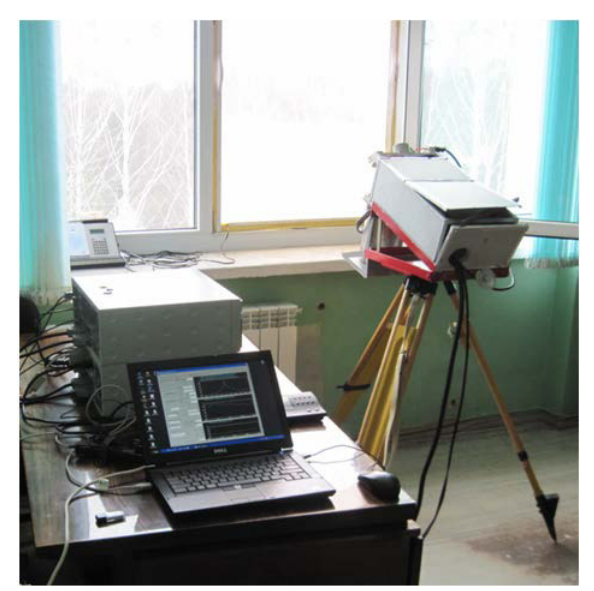

Figure 1. Mobile microwave ozonemeter

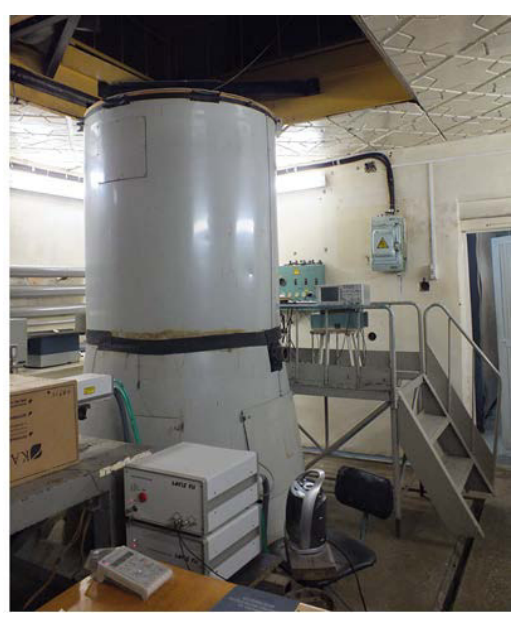

Figure 2. Rayleigh lidar 
The ozone emission spectra were measured by the method of calibration at hot and cold reference loads. To retrieve ozone vertical profiles from measured spectra, we used the model-fitting method [6] with model vertical distributions of pressure and temperature [7]. The uncertainty of retrieval depended on errors of radio measurement and systematic artifacts of the ozone spectrum. Generally, it was about $20 \%$ in the altitude range from 20 up to $60 \mathrm{~km}$.

The vertical temperature distribution was measured by the lidar with a receiving mirror $1 \mathrm{~m}$ in diameter and a transmitter at an Nd: AIG laser with a wavelength of $532 \mathrm{~nm}$, pulse energy of $200 \mathrm{~mJ}$, pulse repetition frequency of $10 \mathrm{~Hz}$, signal accumulation time of $2 \mathrm{~h}$, spatial resolution of $192 \mathrm{~m}$, and signal receiving in the singleelectron photo pulse counting mode. The backscattered radiation was received from altitudes of $15-60 \mathrm{~km}$. The relative error was $2 \%$ at an altitude of $30-40 \mathrm{~km}$. Figure 2 shows the general view of the Rayleigh lidar. The detailed description of joint measurements (technology and methods) can be found in [5]. The observed results were compared with MLS/AURA [8] data and Upperair sounding data from stations Kolpasevo (58.31N, 82.95E) and Novosibirsk $(54.96 \mathrm{~N}, 82.95 \mathrm{E})$ [9].

\section{RESULTS}

Joint observations of temperature (lidar) and ozone (microwave ozonemeter) of the middle atmosphere above Tomsk $(56.5 \mathrm{~N}, 85 \mathrm{E})$ were conducted between December 14, 2012 and January 29, 2013. Observations were carried out every day before and after sunset, weather conditions permitting. Figure 3 depicts variations of total ozone (OMI/AURA), ozone column in the 20-50 km layer (satellite microwave measurements MLS/AURA), and ozone column at altitudes above $22 \mathrm{~km}$ (ground-based microwave measurements) during the observations. Instruments measuring the ozone content observed its decrease and further growth connected with stratospheric warming. The stratospheric warming, during which the lidar and microwave observations were conducted, was of the major type. As a result, the air mass circulation in the upper stratosphere over Western Siberia has changed from westward transport to eastward transport. During winter anomalous events, marked variations of the ozone concentration and temperature in the stratosphere have been observed.

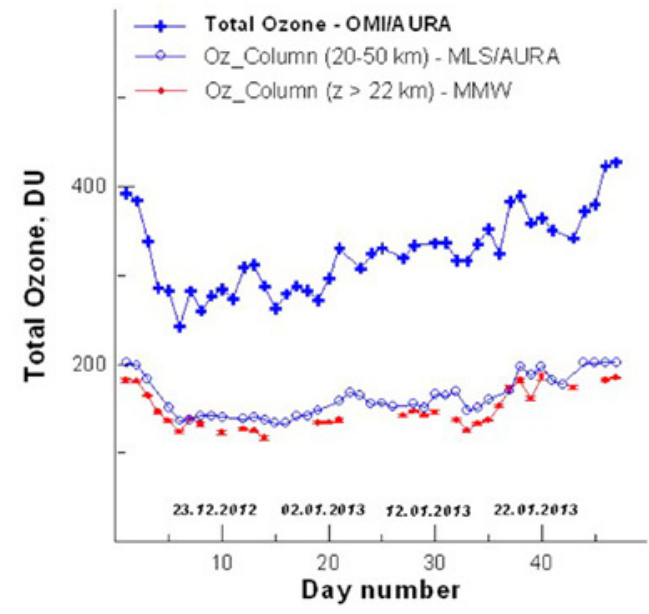

Figure 3. Total ozone (OMI/AURA), ozone content MLS/AURA and MMW (ground-based microwave ozonemeter) versus time during winter 2012/2013 over Tomsk $(56.5 \mathrm{~N}, 85 \mathrm{E})$

Figures 4, 5, 6 illustrate the behavior of ozone density and temperature at altitudes of 25,40 and $60 \mathrm{~km}$ during stratospheric warming. The fact of warming was confirmed by the data of lidar sounding of the high-altitude temperature structure above Tomsk.

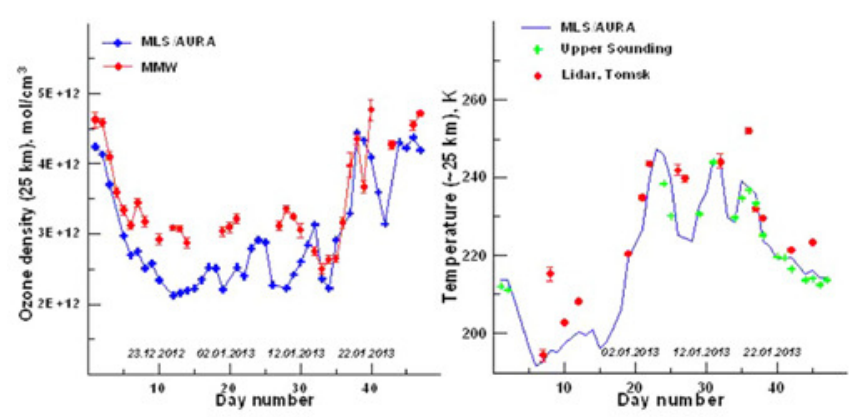

Figure 4. Variations of ozone density and temperature on altitude of $25 \mathrm{~km}$ during stratospheric warming in the winter $2012 / 2013$

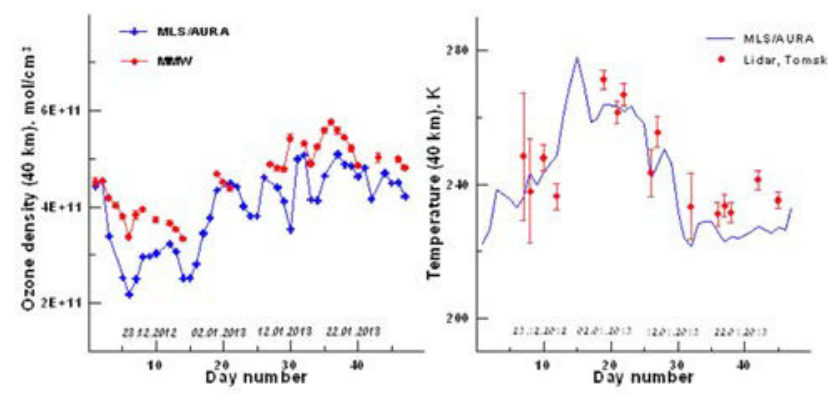

Figure 5. Variations of ozone density and temperature on altitude of $40 \mathrm{~km}$ during stratospheric warming in the winter $2012 / 2013$

The ozone density at altitude levels from 25 to 60 $\mathrm{km}$ varied by 1.5 to 2 times, and the amplitude of 
the variations has increased significantly. It should be mentioned that the diurnal variation (due to sunset and sunrise) of the mesospheric ozone density $(60 \mathrm{~km})$ additionally obtained in our ground-based microwave measurements was, on average, $30 \%$. The peak positive deviation ( 70 $\mathrm{K})$ of temperature from its monthly average value was achieved at an altitude of $30 \mathrm{~km}$.

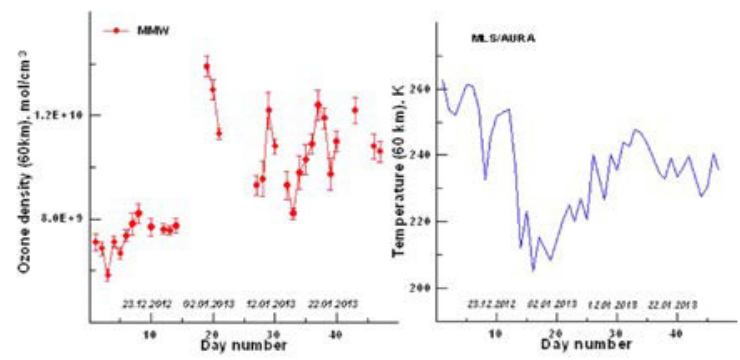

Figure 6. Variations of ozone density and temperature on altitude of $60 \mathrm{~km}$ during stratospheric warming in the winter 2012/2013

Correlations between temperature and ozone variations were found at both the natural and disturbed states of the middle atmosphere. Character of ozone variability depends on the thermal regime of the stratosphere, which, in its turn, is determined by the activity of wave processes in the atmosphere of mid-latitudes.

\section{CONCLUSIONS}

From the results of microwave and optical observations over Tomsk in the period of December-January 2012-2013, the following conclusions can be drawn:

1. The stratospheric warming corresponded to the major type, at which the air mass circulation over the Western Siberia alternated from the western transport to the eastern one.

2. During the anomalous winter events, significant variations of the ozone concentration from 1.5 to 2 times at altitudes from 25 to $60 \mathrm{~km}$ and the considerable growth of the amplitude of these variations were observed. The maximal positive deviation of the temperature from its monthly mean value achieved $\sim 70 \mathrm{~K}$ at an altitude of $30 \mathrm{~km}$.

\section{ACKNOWLEDGEMENT}

This work was supported in part by the Program of basic research of Department of physical sciences of the Russian Academy of Sciences "Atmospheric physics: electrical processes, radiophysical methods of study", Integration Project No. 106 of the Siberian Branch of the Russian Academy of Sciences, the Russian Foundation for Basic Researches (Project 13-0501036a), the President of the Russian Federation (grant NSh-4714.2014.5) and the Project of the Russian Science Foundation № 14-27-00022.

\section{REFERENCES}

[1] Y.Y. Kulikov, A.A. Krasilnikov, V.G. Ryskin, Microwave studies of the structure of the polarlatitude ozone layer during winter anomalous warming events in the stratosphere, Atmos. Oceanic Phys., Vol. 38, pp. 158-166, 2002.

[2] G.G. Matvienko, V.A. Banakh, S.M. Bobrovnikov, V.D. Burlakov, V.V. Veretennikov, B.V. Kaul, G.M. Krekov, V.N. Marichev, The development of atmospheric laser remote sensing technologies, Atmospheric and Ocean Optics, Vol. 22, No. 10, pp. 915-930, 2009.

[3] V.N. Marichev, Lidar investigations of stratospheric warming over Tomsk in 2008-2010, Atmospheric and Ocean Optics, Vol. 24, No. 5, pp. 386-391, 2011.

[4] Y.Y. Kulikov, A.A. Krasilnikov, A.M. Shchitov, New mobile ground-based microwave instrument for research of stratospheric ozone (some results of observation), The Sixth International Kharkov Symposium on Physics and Engineering of Microwaves, Millimeter, and Submillimeter Waves (MSMW' 07) Proceedings, Kharkov, Ukraine, June 25 - 30, Vol. 1. pp. 62 66. 2007.

[5] V.N. Marichev, G.G. Matvienko, A.A. Lisenko, V.Y. Iljushik, Y.Y. Kulikov, A.A. Krasilnikov, V.G. Ryskin, V.V. Byuchkov, First results of complex experiment on sounding the middle atmosphere in optical and millimeter waves (above Tomsk), Atmospheric and Ocean Optics, Vol. 25, No. 12, pp. 1091-1095, 2012.

[6] J. De la Noe, A. Baudry, M. Perault, P. Dierich, N. Monnanteuil, M. Colmont, Measurements of the vertical distribution of ozone by ground-based microwave techniques at the Bordeaux observatory during the June 1981 Intercomparison campaign, Planet., Space Sci., Vol. 16, No. 7, pp. 737-741, 1983.

[7] J.J. Barnett, M. Corney, Middle atmosphere reference model derived from satellite data, Handbook for MAP, Vol. 16, pp. 47-85, 1985.

[8] http://mirador.gsfc.nasa.gov

[9]http://weather.uwyo.edu/upperair/sounding. html 